\title{
Fatores associados à adoção de práticas de gestão financeira por produtores ruraisdo Triângulo Mineiro
}

\author{
Altieres Frances Silva \\ https://orcid.org/0000-0002-9841-672X ｜Ｅ-mail: altieresf@gmail.com \\ Rodrigo Fernandes Malaquias \\ https://orcid.org/0000-0002-7126-1051 | E-mail: rodrigofmalaquias@yahoo.com.br
}

\section{Resumo}

Objetivo do trabalho: $\mathrm{O}$ objetivo principal desta pesquisa é identificar características associadas à adoção de práticas de gestão financeira por produtores rurais do Triângulo Mineiro.

Método: Para a coleta dos dados, foram utilizados questionários. A base de dados foi composta derespostas de 113 produtores rurais que possuem propriedades em 20 cidades do Triângulo Mineiro. O teste das Hipóteses foi realizado a partir da análise de regressão multivariada. Após a obtenção dos resultados, testes adicionais, que abrangeram a utilização de variáveis de interação e a análise fatorial, foram realizados para verificar a robustez do modelo.

Resultados e contribuições do artigo: Os principais resultados indicaram que as práticas de gestão financeira apresentaram relação com a idade do produtor, o conhecimento dos custos de produção, a participação em treinamento sobre gestão financeira e a percepção sobre a relevância da gestão financeira. As possíveis contribuições deste estudo residem na compreensão das características gerenciais de produtores rurais de uma importante região do agronegócio brasileiro e revelam informações que podem subsidiar estratégias do Poder Público, sindicatos rurais, cooperativas rurais, instituições financeiras e demais interessados no aperfeiçoamento da gestão rural.

Palavras-chave: Agronegócio; Gestão Rural; Regionalidade; ProdutoresRurais; Minas Gerais. 


\section{Introdução}

O monitoramento da atividade e a busca por lucratividade, liquidez e solvência estão entre as principais funções do gestor financeiro (Gloy \& LaDue, 2003). Na gestão rural, a observância a essas práticas é de caráter primordial,pois, conforme destacado por Barros, Xavier, Pessoa e Sobel (2015), diversos fatores podem gerar impactos negativos na atividade agropecuária, como as condições climáticas, as doenças e as pragas. Especialmente em um setor permeado por tais incertezas, uma gestão financeira eficaz torna-se ainda mais essencial, uma vez que pode auxiliar na redução e controle dos danos financeiros causados por essas e outras ocorrências associadas.

Nesse sentido, Vogel e Wood Jr. (2012) ressaltaram a relevância da gestão financeira ao associarem a ausência de práticas a ela associadas a cenários emergenciais nos quais as organizações se veem impelidas a captar recursos externos a altas taxas.Ao analisar empresas agrícolas dos Estados Unidos, Khanal e Mishra (2016)destacaram ainda que estratégias gerenciais e controles formais de gestão podem alavancar o desempenho e, considerando-se o uso de tecnologias para o gerenciamento financeiro, fatores como a escolaridade e a idade do produtor rural também podem influenciar a performance, bem como a experiência na atividade - característica identificada por Seramim e Rojo (2016). Para Gloy, Hyde e LaDue (2002), o tamanho da propriedade é outro elemento que pode impactar a adoção de práticas gerenciais. Com base na pesquisa desenvolvida comprodutores de leite dos Estados Unidos, esses autores concluíram que tais práticas podem levar a uma maior lucratividade.

Não obstante os benefícios e o conteúdo informacional gerados a partir dessa gestão, no contexto brasileiro, tem-se observado uma baixa adesão a essas práticas pelo setor rural. Mazzioni et al. (2007) constataram a precariedade de controles e desconhecimento dos resultados por parte dos produtores, características essas também verificadas por Medeiros et al. (2012). Essa ausência de práticas de gestão e controle financeiro pode gerar reflexos negativos no desempenho, conforme observado por Khanal e Mishra (2016), e limitar o crescimento da atividade(Vogel \& Wood Jr., 2012). Além disso, Barros et al. (2015) reafirmaram a relevância da adoção a essas práticas ao constatarem que a gestão financeira pode reduzir o risco de inadimplência no meio rural, enquanto Miottoe Parente (2015) identificaram que o gerenciamento eficaz das finanças pode reduzir o risco de se tornar endividado.

Desse modo, são relevantes e necessários estudos sobre esse tema em virtude da importância que possui a atividade rural para o Brasil. O campo de análise desta pesquisa delimitou-se à região do Triângulo Mineiro, no Estado de Minas Gerais. Este é o detentor da terceira maior participação no PIB brasileiro, entre os estados, e é significativo seu desempenho no agronegócio, uma vez que detém a quarta maior participação de valor adicionado bruto na agricultura do país e a maior participação em relação à produção florestal, à pecuária, à pesca e à aquicultura.Por sua vez, a região do Triângulo Mineiro destacase dentro do estado por seu papel econômico, principalmente na produção rural, visto que três das cincos cidades mineiras com maior valor adicionado bruto ao PIB do estado, no tocante a esse setor, situam-se na referida região. Além disso, cidades do Triângulo Mineiro estão entre as maiores produtoras do estado em relação a diversos itens, como leite, manga, laranja, soja, milho, abacaxi, cana de açúcar, caprinos, galináceos, bovinos e ovinos (IBGE, 2019).

Considerando-se a relevância econômica e social da atividade rural, em especial para a região do Triângulo Mineiro, a importância de se contribuir para que produtores rurais tenham condições financeiras de se manter na atividade e na busca por informações que possibilitem compreender como eles desenvolvem a gestão de suas propriedades, a questão que norteou este estudo foi: Quais fatores podem estar associados à adoção de práticas de gestão financeira por produtores rurais do Triângulo Mineiro? Assim, objetivou-se identificar, por meio de regressões multivariadas, características que podem ser motivadoras para que produtores rurais da referida região adotem práticas de gestão financeira. 
Os resultados obtidos nestapesquisa podem auxiliar no aperfeiçoamento da gestão rural, especialmente em relação aos pequenos produtores que, comumente, possuem menos suporte na administração do negócio. As características identificadas podem aindaauxiliarno desenvolvimento de programas de capacitação por cooperativas e sindicatos rurais e na elaboração ou aperfeiçoamento de políticas por parte do setor público.De modo similar, os achados podem subsidiar políticas de instituições financeiras voltadas ao setor agropecuário em relação à concessão de crédito, linhas de investimento e afins.

Enquanto pesquisas anteriores focaram-se na gestão financeira de cooperativas rurais, na apresentação das características do produtor rural e de sua gestão e em fatores que se correlacionem com a adoção de práticas de gestão(Costa, Chaddad, \& Azevedo, 2012; Imlau et al., 2016; Tarifa \& Schallenberger, 2016; Machado Filho, Caleman,\& Cunha, 2017), nestapesquisabuscaram-se fatoresquepodemdeterminar a adoção a essaspráticas.Desse modo, a pesquisa pode ampliar a literatura sobre o tema ao testar, em conjunto, um grupo de variáveis não observado em estudos anteriores, a partir de dados coletados por meio de um questionário desenvolvido pelos autores e aplicado a uma amostra inédita.

Além dessas contribuições teóricas, França, Mantovaneli Júnior e Sampaio (2012) destacam ainda a relevância de compreender aspectos regionais para o implemento de estratégias que levem a um desenvolvimento integrado. Sob essa perspectiva, estudos como o de Fochezatto e Ghinis (2012), Felema, Raiher e Ferreira (2013) e Sjahza e Asmit (2019) ressaltaram esse ponto de vista. Assim, a análise das características dos produtores rurais sob a perspectiva da regionalidade pode contribuir para o desenvolvimento, além de fornecer subsídios para a elaboração de programas e políticas voltadas ao setor rural, uma necessidade observada porBorges, Guedes e Castro (2016).

Os resultados obtidos a partir deste artigo evidenciaram que capacitar o produtor rural e orientálo sobre a relevância da gestão financeira pode ser fundamental para a adoção e aperfeiçoamento de práticas gerenciais. Embora conheçam seus custos de produção, verificou-se que há uma escassez no uso de ferramentas de controle. Assim, e considerando-se que há a percepção pelos produtores de que a gestão financeira é importante, pode haver um gap em termos de gestão a ser mais bem entendido e explorado, o que proporcionaria contribuições com ganhos de eficiência.

\section{Revisão da literatura e hipóteses do estudo}

Esta pesquisa visa identificar características que podem influenciar a adoção de práticas de gestão financeira por produtores rurais do Triângulo Mineiro, sendo essas práticas entendidas, no presente estudo, como ações relacionadas ao controle de pagamentos e recebimentos, gestão do caixa e de contas bancárias, orçamento ou programação para despesas e investimentos, entre outras relacionadas. As subseções seguintes apresentam as hipóteses que se objetivou investigar como possíveis fatores associados à realização da gestão pelos produtores rurais, sendo de $\mathrm{H} 1$ a $\mathrm{H} 6$ as hipóteses principais e de $\mathrm{H} 7$ a $\mathrm{H} 10$ as correspondentes às possíveis variáveis de controle.

\subsection{A percepção sobre a relevância da gestão financeira}

Ao tratar sobre a percepção de produtores rurais africanos sobre as mudanças climáticas, Pauw (2013) destacou que compreender como o indivíduo visualiza o assunto pode colaborar para o compartilhamento de conhecimentos e para a elaboração de políticas e estratégias, uma vez que a percepção é refletida no comportamento(Nyanga, Johnsen, Aune, \& Kalinda, 2011). Desse modo, é um ponto de interesse verificar se essas associações são aplicáveis em relação à percepção dos produtores rurais quanto às práticas de gestão financeira e, de modo específico, se essa percepção impacta de modo positivo a execução dessa gestão. 
A utilização da percepção como elemento relacionado a uma atitude ou comportamento pode ser observada no estudo de caso desenvolvido por Grøn (2018). Ele analisou aspectos pertinentes à formação e ao desenvolvimento da percepção relativa a implementações gerencias e, para isso, esta foi considerada como variável dependente, enquanto as implementações ocorridas foram utilizadas como variáveis explicativas.

Além disso, O'Reilly (2009) identificou que a percepção dos investidores quanto à opinião do auditor externo relacionada à continuidade da empresa impacta a tomada de decisão e o valor das ações. Khanal e Mishara (2016) e Khan, Tan e Chong (2017) obtiveram indícios de que a percepção do investidor quanto ao retorno obtido anteriormente com portfólios pode influenciar suas decisões relativas à negociação e à exposição ao risco. Robinson, Taylor e Brice (2016), por sua vez, demonstraram que a percepção otimista de executivos em relação ao nível de segurança da informação orientava suas ações associadas ao tema. Assim, considerando-se que a percepção sobre determinado assunto pode refletir nas atitudes e no comportamento dos indivíduos, propõe-se a hipótese de que:

- H1: a percepção sobre a relevância da gestão financeira impacta de modo positivo na adoção de práticas a esta relacionadas.

\subsection{A utilização de ferramentas de controle}

Analisar e controlar o negócio estão entre as tarefas do gestor rural e isso inclui atividades associadas ao controle financeiro (Gloy \& LaDue, 2003), as quais, por sua vez, geram informações que auxiliam no planejamento e na tomada de decisão. Contudo, estudos anteriores demonstraram que no meio rural essas práticas gerenciais - relacionadas ao controle - são pouco utilizadas(Machado \& Nantes, 2011; Oaigen et al., 2013; Simioni, Binotto e Battiston, 2015). Além disso, embora o uso de recursos tecnológicos possa colaborar para o controle dos custos ou outros elementos relacionados à atividade, o que impacta positivamente o gerenciamento da propriedade rural(Machado Filho et al., 2017),esses recursos também são subutilizados e há a necessidade de educar continuamente os produtores sobre o mérito de utilizá-los (Gloy \& LaDue, 2003).

Nesse sentido, Machado e Nantes (2011) observaram que produtores rurais controlam os custos de modo precário. Embora a utilização de planilhas eletrônicas seja uma opção interessante, visto que muitos não têm acesso a softwares especializados que atendam às necessidades da propriedade rural, esses autores destacaram que geralmente essa ferramenta deixa de ser utilizada por falta de conhecimento do produtor. Além do impacto positivo que a adoção de ferramentas de controle proporciona para a eficácia da gestão financeira, especialmente para a identificação dos custos da produção, Oaigen et al. (2013)destacaram que a atitude empresarial e o nível de controle são elementos importantes para a competitividade, mas também verificaram que o uso de ferramentas de gestão por produtores rurais é aquém do esperado, sendo uma característica a ser aperfeiçoada.

No estudo desenvolvido por Simioniet al. (2015) foi destacado o caráter informal de como a gestão é realizada. Os autores identificaram que apenas $17 \%$ dos produtores rurais consultados utilizavam cadernos ou planilhas eletrônicas para o registro dos dados técnicos ou econômicos, o que é uma característica que impacta negativamente a gestão, uma vez que "a maximização e a maior eficiência no uso das tecnologias e do conhecimento e no aproveitamento dos recursos disponíveis na propriedade dependem do adequado processo de gerenciamento e controle de todos os fatores envolvidos na produção"(Simioniet al., 2015, p.168). Assim, o registro dos dados relacionados à atividade contribui de modo positivo para a efetividade da gestão financeira, especialmente por fornecer informações que auxiliam na apuração do resultado, dos índices de rentabilidade, entre outros elementos. 
Ferreira, Lasso e Mainardes (2017), por sua vez, constataram que atitudes, como controlar os gastos empresariais - não os confundindo com os familiares -, conhecer o lucro ou o prejuízo e tomar decisões em momentos de dificuldades financeiras são características que os produtores rurais consideram inovadoras. Além disso, ao identificarem produtores rurais com uma gestão focada no aspecto financeiro, Hey e Morozino (2018) ressaltaram que uma das principais preocupações percebidas é a de obter recursos que cubram os custos da atividade ao final do ciclo produtivo e que haja lucro suficiente para remunerar o trabalho e o uso da propriedade. Isso indica que os produtores que dispendem mais esforças para realizar a gestão financeira tendem a ter controle sobre os custos da produção, corroborando a ideia de que possuir tal controle associa-se de modo positivo à adoção de práticas de gestão financeira. Desse modo, objetivase testar a seguinte hipótese relativa ao controle gerencial:

- H2: a utilização de ferramentas de controle, como planilhas e relatórios, relaciona-se positivamente com a adoção de práticas de gestão financeira pelo produtor rural.

Considerando-se a relevância de conhecer os custos da produção, uma vez que isso possibilita a apuração do resultado, propõe-se testar também a seguinte hipótese:

- H3: o produtor rural ter conhecimento sobre os custos da produção relaciona-se de modo positivo com a adoção de práticas de gestão financeira.

\subsection{O endividamento do produtor rural}

Para Miotto e Parente (2015, p.53), "indivíduos que aplicam um melhor gerenciamento de suas receitas e despesas tendem a evitar situações nas quais seus gastos excedem seus ganhos, reduzindo assim seu risco de inadimplência”. Eles identificaram que, entre famílias brasileiras de classe média baixa, desenvolver um planejamento e realizar a administração financeira tende a associar-se positivamente a baixas situações de inadimplência. Uma vez que parte considerável da produção rural é desenvolvida no âmbito familiar (MAPA, 2017), é um fator de interesse verificar se essa relação aplica-se ao produtor que se considera endividado, o que poderia contribuir para sua adimplência - especialmente considerando-se a possibilidade de haver dívidas tomadas para fins não produtivos, que não geram receita adicional(Datta, Tiwari, \& Shylajan, 2018).

Sob a perspectiva das pequenas e médias empresas de Minas Gerais, Camargos, Camargos, Silva, Santos e Rodrigues (2010) também identificaram, entre os fatores condicionantes da inadimplência, aspectos relacionados à gestão financeira, em especial à administração do capital de giro. Para a atividade agropecuária, Barros et al. (2015) observaram que, entre os produtores rurais da amostra utilizada, houve aproximadamente $50 \%$ de chances de ocorrer o não pagamento das dívidas e que a execução de práticas de gestão financeira foi um dos fatores que pesaram positivamente para a adimplência. Assim, os resultados apontam que as ferramentas e ações relacionadas ao gerenciamento financeiro do negócio auxiliam, de modo positivo, na redução do risco de o produtor endividado tornar-se inadimplente. Desse modo, partindo da premissa de que o produtor rural endividado adota práticas de gestão para que não se torne inadimplente, objetiva-se testar a seguinte hipótese:

- H4: o produtor rural considerar-se endividado gera reflexos positivos na adoção de práticas de gestão financeira. 


\subsection{A inadimplência dos clientes}

De modo semelhante às justificativas mencionadas em relação ao endividamento do produtor rural e das ações gerenciais que ele pode adotar a fim de não se tornar inadimplente, importa analisar se a inadimplência por parte dos clientes impacta positivamente a adoção de práticas de gestão financeira pelo produtor rural, fator que pode subsidiá-lo para a adequação de suas estratégias de venda e de seus prazos médios operacionais e financeiros.

Além da relevância dos controles e ferramentas financeiras que auxiliam os gestores a terem controle sobre suas dívidas (Barros et al., 2015), corroborando para que sejam adimplentes e, em certos casos, até evitando a assunção de obrigações, a gestão financeira também pode contribuir para a redução do risco de inadimplência dos clientes ou, caso ela ocorra, pode fornecer ao gestor informações necessárias à adequação de seu orçamento e do planejamento financeiro. Nesse sentido, Castagnolo e Ferro (2014), Duan, Kim, Kim e Shin (2018) e Gabbianelli (2018) evidenciaram a associação positiva da informação financeira para a melhoria de aspectos relacionados à redução ou à predição do risco de inadimplência, enquantoCrespi Júnior, Perera e Kerr (2017) destacaram como ações relacionadas à gestão financeira podem evitar ou conter danos causados por maus pagadores. Assim, objetiva-se testar a hipótese:

- H5: a inadimplência dos clientes ser percebida pelo produtor rural como uma dificuldade impacta positivamente para que ele adote práticas de gestão financeira.

\subsection{A capacitação profissional do produtor rural}

Ao treinar o produtor rural a lidar com rotinas ou ferramentas gerenciais, este pode aprender a aplicá-las, aperfeiçoando suas práticas de gestão. A capacitação pode ainda auxiliar o produtor no uso de recursos tecnológicas para fins gerenciais, o que contribui para a otimização de seu tempo e aceleramento dos processos (Islam, Habes\& Alam, 2018). Desse modo, o produtor capacitar-se pode ser um fator chave para uma gestão financeira eficaz.

Zanin, Oenning, Tres, Kruger e Gubiani (2014) associaram a não participação em cursos de treinamento à ausência de controles que auxiliem na tomada de decisão dos produtores rurais, demonstrando que a capacitação do produtor pode influenciar positivamente a adoção e execução de melhores práticas de gestão. Nesse sentido, Martínez-García, Ugoretz, Arriaga-Jordán e Wattiaux (2015) identificaram, por meio da análise de cluster, que produtores rurais que acessam programas de capacitação e que utilizam serviços de cooperativas têm uma produção superior aos demais grupos, formados ou por produtores mais velhos e mais experientes ou por produtores mais jovens e com mais anos de educação formal.

Ao identificar produtores rurais que utilizam de modo precário ferramentas de gestão financeira e operacional, Simioniet al.(2015) afirmaram que há necessidade de se ampliar programas de qualificação, sugerindo, assim, que a capacitação do produtor impacta positivamente a gestão, tanto financeira quanto em relação ao processo produtivo. Latawiec etal. (2017), por sua vez, destacaram o déficit de acesso à extensão técnica como fator que impede a adoção de melhores práticas de manejo, o que, segundo parte dos produtores rurais consultados por eles, levaria a um melhor gerenciamento administrativo da propriedade. Em outras palavras, houve a percepção de que qualificar o produtor contribui positivamente para uma melhor gestão, ainda que os cursos ou treinamentos sejam voltadas para aspectos operacionais. Além destes, estudos como os de Kumar e Shrestha (2014), Huang, Vyas e Liang (2015) e Nakano, Tsusaka, Ainda e Pede (2018) também destacaram a relevância de se capacitar o produtor rural. Assim, tendo em vista os argumentos apresentados, visa-se testar a seguinte hipótese: 
- H6: a participação em treinamentos sobre gestão financeira impacta positivamente a adoção de práticas relacionadas a esta.

\subsection{O nível de escolaridade do produtor rural}

Ao ascender os níveis formais de ensino, supõe-se que o gestor desenvolva diferentes habilidades pessoais e profissionais que, direta ou indiretamente, possam contribuir para seu aperfeiçoamento nessa função. Assim, haveria uma maior probabilidade de os produtores rurais com um maior nível de escolaridade possuírem um melhor desempenho na atividade gerado pela aplicação na gestão do conhecimento adquirido por meio do ensino formal.

Essa associação é comumente investigada na literatura. Gloyet al. (2002, p.242) afirmaram que "o nível de educação formal do produtor rural é uma medida da qualidade do capital humano estocado na propriedade". Apesar disso, eles não obtiveram em seu estudo uma relação significativa entre a educação formal e a rentabilidade do produtor. De modo semelhante, Simioniet al. (2015) não verificaram relação significativa da escolaridade do produtor rural com o aumento de sua renda. Já Wilson, Mishra e Williams (2009) identificaram que as propriedades gerenciadas por produtores jovens possuíam um desempenho inferior. Eles destacaram, taisquaisMartínez-García et al. (2015), que esse resultado não decorre necessariamente de uma gestão ineficiente, mas das possibilidades de obter retornos provenientes do trabalho não agrícola, de modo a comprometer a administração da propriedade, gerando assim uma associação negativa entre práticas de gestão financeira e o nível de escolaridade.

Oaigen et al. (2013), por sua vez, constataram que produtores rurais da região Sul possuem maior nível de escolaridade do que os da região Norte do Brasil e que são mais competitivos, sendo a utilização de indicadores financeiros e o planejamento estratégico alguns dos fatores críticos a essa competitividade. Já os resultados do estudo de Barros et al. (2015) demonstraram que a probabilidade de o produtor rural ser inadimplente reduz caso ele possua nível superior. Uma gestão financeira eficaz contribui para um melhor controle e planejamento em relação aos recursos da empresa, o que pode reduzir o risco de inadimplência, além de fornecer ferramentas que auxiliam na análise do negócio, como os indicadores financeiros. Dessa forma, não obstante a diversidade de resultados observados na literatura quanto a essa variável, objetivase testar a seguinte hipótese relativa à educação formal:

- H7: o nível de escolaridade do produtor rural impacta positivamente na adoção de práticas de gestão financeira.

\subsection{O tamanho da propriedade rural}

Aspectos relacionados à performance financeira e à obtenção de margens de lucro satisfatórias podem ser positivamente associadas à adoção de boas práticas de gestão financeira, visto ser esperado que essas forneçam a estrutura necessária para o conhecimento de informações úteis à tomada de decisão. Conjectura-se que essas práticas sejam mais comumente observadas em propriedades rurais de maior porte, visto que elas tenderiam a possuir mais recursos humanos, financeiros e tecnológicos para investir nesse gerenciamento, além de possivelmente possuir um maior volume de operações. 
Por essa ótica,Gloy et al. (2002) identificaram que o tamanho da propriedade relaciona-se positivamente com o desempenho financeiro e as diferenças na lucratividade de propriedades que se assemelham podem ser atribuídas a fatores gerenciais. Já Zanin et al. (2014) constataram a partir de uma amostra formada por 124 produtores rurais, sendo $81 \%$ das propriedades caracterizadas como de pequeno porte, que em $54 \%$ delas não havia controles gerenciais suficientes para a tomada de decisão nem se utilizavam de relatórios gerenciais ou da contabilidade rural. Simioniet al. (2015), por sua vez, analisaram uma amostra em que mais de $81 \%$ das propriedades rurais eram de pequeno porte e identificaram que as ações gerenciais eram básicas e informais, sem registros nem controle dos processos.

Machado Filho et al. (2017) observaram uma relação positiva entre o tamanho de propriedades rurais e a adoção de práticas de controle necessárias ao implemento da contabilidade e de mecanismos de governança. Eles destacaram como uma possível razão dessa característica a maior incidência de funcionários contratados existentes nessas propriedades, o que possibilita que o produtor dedique mais tempo à gestão.De modo semelhante, Lai, Widmar e Wolf (2019) verificaram que fazendas de grande porte tendem a priorizar a gestão financeira, enquantoNdemewah, Menges e Hiebl (2019) obtiveram resultados que indicaram o uso reduzido de práticas de contabilidade gerencial em pequenas propriedades.

De modo adicional, pode-se fazer um paralelo entre o tamanho da propriedade rural, o ciclo de vida do negócio e as práticas de gestão adotadas. Para Miller e Friesen (1984, p.1161), "é esperado que ocorram certas transições à medida que empresas jovens e pequenas crescem, envelhecem e se tornam mais complexas", sendo que o uso de sistemas e controles gerencias está dentre os elementos que permitem classificá-las nos diferentes estágios de vida. Isso foi observado porAuzair e Langfield-Smith (2005), que identificaram que esses diferentes estágios influenciam no design dos sistemas de controle gerencial de organizações australianas, e por Davila e Foster (2005), ao analisarem startups norte-americanas, em queconstataram que o uso de ferramentas gerenciais, como os orçamentos operacionais, torna-se mais presente à medida que as empresas se expandem.

Diante do exposto, tem-se a seguinte hipótese a ser testada neste estudo em relação ao tamanho da propriedade:

- H8: há uma relação positiva entre o tamanho da propriedade e a adoção de práticas de gestão financeira.

\subsection{A idade e a experiência do produtor rural}

As características do produtor rural, tais quais a idade e a experiência na atividade, podem ser fatores influenciadores do desempenho financeiro. Pressupõe-se que produtores com mais anos de experiência na atividade rural possuem um melhor entendimento do negócio, de fatores que podem impactar negativamente suas finanças, e, assim, tendem a possuir práticas mais acuradas de gestão, aperfeiçoadas ao longo do tempo de acordo com suas vivências. Uma vez que essa experiência é adquirida ao longo do tempo, a idade do produtor rural também seria uma variável passível de influenciar a adoção de práticas gerenciais, sendo que outras características relacionadas à idade também poderiam gerar esse efeito, como o grau de responsabilidade assumido, a consolidação no mercado e uma maior estabilidade financeira. 
O impacto da idade na gestão rural foi observado por Wilsonet al. (2009), que identificaram que o desempenho financeiro é inferior quando os produtores são jovens e superior quando são mais velhos. Por sua vez, Barros et al. (2015, p.190) constataram que "produtores de maior faixa etária tendem a ter maior compromisso de pagamento de suas dívidas". Em outras palavras, a probabilidade de ser inadimplente reduz com o aumento da idade, característica que pode indicar que a idade do produtor influencia positivamente a utilização ou a qualidade das práticas de gestão financeira adotadas. Simioni et al. (2015), contudo, não identificaram uma tendência de relação entre a renda e a idade do produtor rural, ao passo que os resultados obtidos por Brown, Daigneault e Dawson (2019) demonstraram uma associação positiva entre idade e priorização da gestão financeira. Contudo, a correlação obtida por estes autores foi positiva apenas até 58 anos de idade, tornando-se negativa daí em diante. Segundo eles, após essa idade os produtores tendem a mudar seu estilo de vida, o que diminui a prioridade dada até então às práticas de gestão financeira.

Em relação à experiência, Martínez-García et al. (2015) observaram que produtores mais jovens tendem a ter menos tempo de atuação, enquanto Seramim e Rojo (2016)identificaram que o tempo de experiência do produtor gera reflexos na lucratividade e na sustentabilidade econômica da atividade. Associações semelhantes foram obtidas considerando-se outros setores de atuação (Mion\& Opramolla, 2014;Matemilola, Bany-Ariffin \& Azman-Saini, 2018). Assim, possuir experiência tende a associar-se a uma maior probabilidade de resultados financeiros positivos (Eschker, Gold, \& Lane, 2017). Na busca por uma geração de lucro consistente e contínua, práticas de gestão financeira, como o controle dos custos e das despesas, apresentam-se como fatores relevantes e necessários, inclusive para que o gestor tenha conhecimento do resultado.

Não obstante os resultados desses estudos, Hey e Morozini (2018) analisaram por meio de cluster a relação entre estratégias e o ciclo produtivo de commodities agrícolas e, entre os produtores com até 10 anos de atuação, $50 \%$ foram alocados ao grupo que tinha como foco a gestão financeira. Entre aqueles com mais de 11 anos de experiência, esse percentual foi de 38\%, indicando que produtores com menos anos de atuação focaram-se mais na gestão financeira. A compensação do tempo de experiência por um nível maior de escolaridade por parte dos produtores mais jovens levaria a um melhor desempenho gerencial, sendo uma possível razão para o resultado obtido. Nesse caso, o tempo de experiência do produtor não se relacionaria positivamente às ações concernentes à gestão financeira.Considerando-se os fatores expostos, objetiva-se testar as seguintes hipóteses:

- H9: a idade do produtor influencia positivamente na adoção de práticas de gestão financeira.

- H10: a experiência como produtor rural influencia positivamente na adoção de práticas de gestão financeira.

\section{Procedimentos metodológicos}

A amostra analisada neste estudo foi composta por 113 produtores rurais da região do Triângulo Mineiro, no Estado de Minas Gerais. O levantamento dos dados ocorreu pelo método survey, por meio do qual foi aplicado o questionário desenvolvido para esta pesquisa àqueles produtores rurais que se dispuseram a respondê-lo e que concordaram com o expresso no Termo de Consentimento Livre e Esclarecido (TCLE). No total, houve 116 participantes, tendo-se optado pela exclusão de três questionários que não foram respondidos integralmente. O projeto desta pesquisa, juntamente com o questionário elaborado a partir das referências investigadas, foi submetido e aprovado, no mês de dezembro de 2018, pelo Comitê de Ética em Pesquisas com Seres Humanos (CEP) da Universidade Federal de Uberlândia. 
A aplicação dos questionários ocorreu entre os meses de janeiro e abril de 2019 e concentrou-se em sindicatos rurais, leilões de gado, feira de agronegócio, feiras de produtos agroecológicos e no setor de atendimento ao público do Instituto Mineiro de Agropecuária (IMA). Ao início da abordagem, os possíveis participantes foram questionados se eram produtores rurais. Uma vez obtida a confirmação de que assim se caracterizavam, foi-lhes apresentado o TCLE, que incluiu esclarecimentos referentes ao objetivo do estudo, e fornecido o questionário da pesquisa.

Os participantes foram comunicados de que a participação era voluntária, que não haveria ganhos nem dispêndio de recursos pela participação e que não teriam a identidade revelada. $O$ tempo médio de resposta foi de quinze minutos, tendo os autores do estudo aguardado junto ao respondente até que este finalizasse sua participação.

As propriedades rurais dos 113 participantes distribuem-se pelos municípios de Araguari, Capinópolis, Cascalho Rico, Estrela do Sul, Ibiá, Indianópolis, Itarumã, Ituiutaba, Lagamar, Monte Alegre de Minas, Prata, Romaria, Tapuirama, Tupaciguara, Uberaba e Uberlândia. Além destas cidades do Triângulo Mineiro, houve participantes que possuíam propriedades nestes municípios e em outras localidades, razão pela qual se inclui nessa relação às cidades de Buritizeiro, Lagoa dos Patos e Várzea do Sul, no norte de Minas, e Cachoeira Alta, no sul do Estado de Goiás.

$\mathrm{Na}$ identificação dos possíveis fatores associados à adoção de práticas de gestão financeira pelos produtores rurais, realizou-se uma análise de regressão multivariada. Optou-se por aplicar o modelo de regressão com erros-padrão robustos a fim de que as variâncias fossem estimadas de modo consistente ainda que alguma forma de heterocedasticidade estivesse presente na amostra.A gestão financeira realizada pelo produtor (GF_Realizada) foi a variável dependente do estudo, obtida pela média das respostas registradas para os itens de 7 a 12 do instrumento de pesquisa e sobre a qual se testou a influência das variáveis explicativas apresentadas na Tabela 1. É oportuno mencionar que as respostas para cada um dos itens da variável GF_Realizada foram obtidas por meio da escala Likert de 1 ("discordo fortemente") a 5 ("concordo fortemente"). 
Tabela1

Variáveis utilizadas no estudo

Variável dependente: Gestão financeira realizada - GF_Realizada (Obtida por meio da escala Likert de 5 pontos) Itens correspondentes no instrumento de pesquisa:

Q7. A gestão financeira é realizada pelo produtor rural?

Q8. A gestão de caixa/bancos é realizada pelo produtor rural?

Q9. O controle de pagamentos é realizado pelo produtor rural?

Q10. O controle de recebimentos é realizado pelo produtor rural?

Q11. O orçamento/programação de despesas é realizado pelo produtor rural?

Q12. O orçamento/programação de novos investimentos é realizado pelo produtor rural?

\begin{tabular}{|c|c|}
\hline \multicolumn{2}{|r|}{ Variáveis explicativas } \\
\hline Variável & Item correspondente no instrumento de pesquisa: \\
\hline $\begin{array}{l}\text { Relevância da Gestão } \\
\text { financeira - GF_Relevância } \\
\text { (Obtida por meio da } \\
\text { escala Likert de } 5 \text { pontos) }\end{array}$ & $\begin{array}{l}\text { Q1. A gestão financeira é relevante para o produtor rural? } \\
\text { Q2. A gestão de caixa/bancos é relevante para o produtor rural? } \\
\text { Q3. O controle de pagamentos é relevante para o produtor rural? } \\
\text { Q4. O controle de recebimentos é relevante para o produtor rural? } \\
\text { Q5. O orçamento/programação de despesas é relevante para o produtor rural? } \\
\text { Q6. O orçamento/programação de novos investimentos é relevante para o produtor rural? }\end{array}$ \\
\hline $\begin{array}{l}\text { Utilização de } \\
\text { ferramentasde controle }\end{array}$ & Q22. Existem ferramentas de controle financeiro e da produção (ex.: relatórios, planilhas...)? \\
\hline Conhecimento dos custos & Q18. O produtor conhece o custo dos produtos que vende? \\
\hline Endividamento & Q17. O produtor considera-se endividado? \\
\hline $\begin{array}{l}\text { Inadimplência dos } \\
\text { clientes }\end{array}$ & Q13. A inadimplência dos clientes representa uma dificuldade para o produtor rural? \\
\hline $\begin{array}{l}\text { Treinamento/ } \\
\text { Capacitação }\end{array}$ & Q19. Já participou de algum treinamento sobre gestão financeira? \\
\hline Escolaridade & $\begin{array}{l}\text { Q23. Possui curso técnico? } \\
\text { Q24. Possui curso de graduação? } \\
\text { Q25. Possui curso de especialização? } \\
\text { Q26. Possui curso de mestrado ou doutorado? }\end{array}$ \\
\hline Tamanho (In) & Q14. Tamanho da propriedade (em hectares) \\
\hline Idade & Q15. Idade do Produtor Rural (em anos) \\
\hline Experiência & Q16. Tempo de experiência como produtor rural (em anos) \\
\hline
\end{tabular}

Fonte: elaborado pelos autores.

Assim como a GF_Realizada, a variável explicativa que se refere à percepção do produtor rural quanto à relevância das práticas de gestão financeira (GF_Relevância) foi obtida pela média das respostas para um grupo de questões, cujas respostas estão baseadas na escala Likert de 1 ("discordo fortemente") a 5 ("concordo fortemente"). A confiabilidade desses construtos foi verificada e atestada por meio do alfa de Cronbach, uma vez que para ambas o coeficiente obtido foi superior aos 0,70 recomendados pela literatura(Hairet al., 2009; Bagozi\&Yi, 2011).

A variável explicativa referente à percepção do produtor rural sobre a inadimplência dos clientes ser uma dificuldade também foi mensurada por meio da escala Likert, ao passo que as variáveis relativas ao endividamento, ao conhecimento dos custos de produção, à utilização de ferramentas de controle e à participação em treinamentos sobre gestão financeira foram geradas a partir de questões dicotômicas, cujas respostas foram "sim" ou "não". 
Cada item relacionado ao nível de educação formal do produtor rural, por sua vez, recebeu um ponto, de modo que a variável escolaridade representa o somatório desses scores, ou seja, para cada produtor foi atribuída uma pontuação de 0 a 4 . Assim, para o produtor rural detentor dos quatro níveis de ensino apresentados (técnico, superior, especialização e mestrado/doutorado), foram atribuídos 4 pontos; para o produtor rural com apenas o curso técnico, por exemplo, atribuiu-se 1 ponto; o produtor rural não possuidor de nenhum desses níveis de escolaridade não obteve pontuação. Desse modo, o modelo testado neste estudo baseou-se na equação:

$$
\begin{gathered}
\text { GF_Realizada }=\beta_{0}+\beta_{1} \text { GF_Relevância }+\beta_{2} \text { Controles }+\beta_{3} \text { Custos }+\beta_{4} \text { Endiv }+ \\
\beta_{5} \text { Inadim }+\beta_{6} \text { Capacit }+\beta_{7} \text { Escolar }+\beta_{8} \text { Tam }+\beta_{9} I d+\beta_{10} \text { Exper }+\varepsilon
\end{gathered}
$$

em que:

- GF_Realizada = média das respostas referentes à adoção de práticas de gestão financeira (itens de Q7 até Q12), podendo variar, assim, entre 1 e 5;

- GF_Relevância = média das respostas referentes à percepção sobre a relevância das práticas de gestão financeira (itens de Q1 até Q6), podendo variar, assim, entre 1 e 5;

- $\quad$ Controles = dummy para utilização de ferramentas de controle, como planilhas e relatórios, atribuindo-se 1 para produtores que responderam "sim" e 0 nos demais casos;

- $\quad$ Custos = dummypara conhecimento dos custos de produção, atribuindo-se 1 para produtores que responderam "sim" e 0 nos demais casos;

- Endiv = dummypara produtores rurais endividados, atribuindo-se 1 aos produtores que responderam "sim" e 0 para os demais casos;

- Inadim = percepção do produtor sobre a inadimplência dos clientes ser uma dificuldade, respondida por meio da escala Likert de 1 a 5;

- Capacit $=$ dummypara participação em cursos de treinamento/capacitação em gestão financeira, atribuindo-se 1 aos produtores que responderam "sim" e 0 para os demais casos;

- Escolar = somatório das respostas para as quatro questões referentes aos níveis de escolaridade, atribuindo-se, em cada questão, 1 aos produtores que responderam "sim" e 0 para os demais;

- $\quad$ Tam = logaritmo natural do tamanho da propriedade rural, em hectares;

- $\quad \mathrm{Id}=$ idade do produtor rural, em anos;

- $\quad$ Exper = experiência do produtor rural, em anos;

- $\beta=$ coeficiente regressor de cada variável;

- $\varepsilon=$ termo de erro da regressão.

A Tabela 2, a seguir, evidencia a estatística descritiva das variáveis do estudo. O Painel A resume as informações relativas às variáveis escalares, enquanto o Painel B contém as informações das variáveis dicotômicas: 
Tabela 2

\section{Estatística descritiva das variáveis do estudo}

\begin{tabular}{|c|c|c|c|c|c|}
\hline \multicolumn{6}{|l|}{ Painel A } \\
\hline Variáveis Escalares & $\mathbf{n}$ & Média & Desv. Padr. & Mín. & Máx. \\
\hline GF-Realizada & 113 & 3,941 & 0,797 & 1,667 & 5 \\
\hline GF-Relevância & 113 & 4,661 & 0,427 & 3,167 & 5 \\
\hline Tamanho (hectares) & 113 & 244,92 & 337,9 & 3 & 1700 \\
\hline Tamanho (Ln) & 113 & 4,607 & 1,490 & 1,099 & 7,438 \\
\hline Idade (anos) & 113 & 52,575 & 15,24 & 21 & 85 \\
\hline Experiência (anos) & 113 & 25,717 & 16,17 & 2 & 77 \\
\hline Escolaridade & 113 & 0,912 & 1,023 & 0 & 4 \\
\hline Inadimplência & 113 & 4,363 & 1,009 & 1 & 5 \\
\hline \multicolumn{6}{|l|}{ Painel B } \\
\hline Variáveis Dicotômicas & $\mathbf{n}$ & Sim & Não & & \\
\hline Possui Ferram. Contr.? & 113 & $54,87 \%$ & $45,13 \%$ & & \\
\hline Conhec. Custo Produção? & 113 & $79,65 \%$ & $20,35 \%$ & & \\
\hline Treinam. Gest. Financ.? & 113 & $42,48 \%$ & $57,52 \%$ & & \\
\hline Endividado? & 113 & $13,27 \%$ & $86,73 \%$ & & \\
\hline
\end{tabular}

Em uma escala de 1 a 5, a relevância da gestão financeira obteve média de 4,661, demonstrando que, no geral, os produtores rurais a percebem como importante para a atividade. Apesar disso, e considerandose a mesma escala, a adoção de práticas relacionadas à gestão financeira foi, em média, de 3,941, indicando que os produtores percebem algumas práticas como relevantes, mas não as adotam ou as realizam de modo precário.

O perfil dos componentes da amostra foi diverso e abrangeu desde produtores rurais jovens e com poucos anos de experiência a produtores octogenários e que estão há décadas exercendo a atividade, o que pode ser constatado a partir da média e da mediana da idade (52,58 e 53 anos, respectivamente) e da experiência como produtor rural (25,71 e 20 anos, respectivamente). O tamanho médio das propriedades foi de 245 hectares, com a mediana em 120 hectares. Em relação à escolaridade, 27\% dos participantes possuem curso técnico, $42 \%$ são graduados, $19 \%$ cursaram especialização e $4 \%$ são mestres ou doutores. Por outro lado, aproximadamente $45 \%$ dos respondentes não possuem nenhum desses níveis de educação formal.

A média quanto à percepção do produtor rural sobre a inadimplência de os clientes representar uma dificuldade, também mensurada na escala Likert, foi de 4,363. Ou seja, a maioria dos participantes concordaram que os clientes não saldarem suas dívidas com o produtor representa uma dificuldade para este.

Em torno de 13\% dos respondentes consideraram-se endividados. Entre estes, a média de adoção às práticas de gestão financeira foi de 3,72, inferior à média de 3,97 observada entre aqueles que não se consideraram endividados. Quanto à ciência sobre os custos de produção, 79,65\% dos produtores afirmaram que saberiam dizer os custos incorridos até que o produto esteja pronto para a venda. Apesar disso, apenas 54,87\% declarou utilizar ferramentas de controle, como relatórios e planilhas. O Apêndice A contém a matriz de correlação entre as variáveis do estudo. 


\section{Resultados}

Com a finalidade de testar quais fatores podem influenciar a adoção de práticas de gestão financeira pelos produtores rurais, aplicou-se a regressão multivariada com erros-padrão robustos, cujos resultados encontram-se na Tabela 3:

Tabela 3

\section{Resultados da regressão multivariada}

\begin{tabular}{|c|c|c|c|c|}
\hline Variáveis & Coef. & $\begin{array}{c}\text { Erro } \\
\text { Padrão Rob. }\end{array}$ & $\mathbf{t}$ & signif. \\
\hline GF_Relevância & 0,493 & 0,158 & 3,12 & $0,002 * * *$ \\
\hline Ferramentas de Controle & 0,139 & 0,133 & 1,04 & 0,300 \\
\hline Conhecimento Custos de Produção & 0,525 & 0,192 & 2,73 & $0,007 * * *$ \\
\hline Endividamento & $-0,206$ & 0,171 & $-1,21$ & 0,229 \\
\hline Inadimplência & 0,048 & 0,068 & 0,71 & 0,479 \\
\hline Treinamento em Gestão Financeira & 0,387 & 0,141 & 2,74 & $0,007 * * *$ \\
\hline Escolaridade & 0,015 & 0,078 & 0,20 & 0,844 \\
\hline Tamanho (Ln) & 0,047 & 0,040 & 1,17 & 0,246 \\
\hline Idade (anos) & 0,013 & 0,005 & 2,44 & $0,016 * \star$ \\
\hline Experiência (anos) & $-0,004$ & 0,005 & $-0,80$ & 0,423 \\
\hline Constante & $-0,028$ & 0,793 & $-0,04$ & 0,972 \\
\hline número de observações: & 113 & & & \\
\hline r-quadrado: & $36,46 \%$ & & & \\
\hline r-quadrado ajustado: & $30,23 \%$ & & & \\
\hline VIF (média): & 1,36 & VIF (máximo): & 1,77 & \\
\hline
\end{tabular}

Notas: ${ }^{*} p<0.10 ; * \star p<0.05 ; * \star * p<0.01$.

Fonte: Resultados da pesquisa.

A média do coeficiente relacionado ao fator de inflação de variância (VIF) foi de 1,36, indicando a não existência de multicolinearidade entre as variáveis. $\mathrm{O} r$-quadradoajustado demonstrou que o modelo proposto explica $30,23 \%$ da variação observada na gestão financeira realizada pelo produtor rural. Considerando-se a significância observada, os resultados da regressão apresentaram indícios de que a idade do produtor rural, o conhecimento sobre os custos de produção, a participação em treinamentos e a percepção quanto à relevância da gestão financeira influenciam,positivamente,a efetiva adoção de práticas a ela associadas.

Antes de iniciar a discussão das hipóteses, foi realizada uma análise adicional, tendo em vista a correlação positiva, moderada e significativa entre as variáveis idade e experiência. Embora a estatística VIF tenha sugerido ausência de multicolinearidade, a matriz de correlação (Apêndice A) sugere que as variáveis idade e experiência possuem correlação moderada. Desta forma, o modelo quantitativo foi estimado novamente, alternando-se as variáveis idade e experiência. Os resultados estão disponíveis no Apêndice B e, de maneira geral, mostram-se equivalentes aos apresentados na Tabela $3 \mathrm{em}$ termos de sinal e nível de significância para as demais variáveis do modelo (exceto para a variável Treinamento em Gestão Financeira, que foi significativa a $1 \%$ no modelo geral e no modelo sem a variável idade, passando a ser significativa a $5 \%$ no modelo sem a variável experiência). 
A partir dos resultados obtidos,não se rejeitou a hipótese $\mathrm{H} 1$ de que a percepção do produtor rural sobre a relevância da gestão financeira influencia a adoção de práticas a ela associadas. Essa relação corrobora a afirmação de Nyanga et al. (2011) de que a percepção é refletida no comportamento e, além disso, vai ao encontro de estudos anteriores que relataram a associação entre percepção e comportamento (Robinson, Taylor, Brice, 2016; Khan, Tan, Chong, 2017). Nesse sentido, constata-se a importância de fatores que podem influenciar a percepção do produtor rural quanto à gestão financeira, uma vez que os resultados indicaram a associação entre essa percepção e a efetiva adoção das práticas a ela relacionadas.

O conhecimento sobre os custos de produção é outra variável que possibilita identificar produtores que adotam práticas de gestão financeira, visto que houve significância para a hipótese H3, a qual afirma que a ciência sobre esses custos impacta positivamente nas práticas gerenciais. Apesar disso, os resultados da regressão relativos a essa variável não permitem discordar de Machado e Nantes (2011), que afirmaram que produtores rurais controlam os custos de modo precário e têm dificuldade de utilizar ferramentas de controle, como planilhas eletrônicas. Isso porque, conforme destacado anteriormente, observou-se que há produtores que dizem possuir conhecimento de seus custos, mas que não utilizam ferramentas de controle. Ademais, não houve significância estatística para a hipótese $\mathrm{H} 2$, relativa à associação positiva entre utilização de controles e a adoção de práticas de gestão financeira.

A significância da hipótese H3 pode decorrer do fator relatado por Hey e Morozino (2018). Segundo eles, produtores rurais que focam sua gestão no aspecto financeiro têm conhecimento de seus custos, pois a principal preocupação observada é a obtenção de lucro suficiente para remunerar o trabalho e a propriedade. Assim, o controle dos custos tende a estar entre as práticas comumente adotadas entre os produtores que mantêm a gestão financeira sob foco. Uma vez que este estudo não teve por objetivo identificar os diferentes perfis gerenciais dos gestores rurais, não se pode afirmar que, de fato, a significância decorra dessa justificativa. Todavia, a significância da hipótese $\mathrm{H} 3$ e o efeito não significativo de $\mathrm{H} 2$ pode indicar que os produtores rurais adotam apenas práticas de gestão financeira suficientes para o conhecimento de seus custos.

A hipótese H6 sobre o impacto positivo do treinamento ou da capacitação em gestão financeira na adoção de práticas relacionadas a essa gestão também não foi rejeitada. Isso vai ao encontro dos resultados de Zanin et al. (2014), que indicaram a influência positiva da capacitação profissional na adoção e execução de melhores práticas gerenciais, bem como alinha-se à percepção de Simioni, Binotto e Battiston (2015) quanto à associação positiva entre capacitação e gestão. Assim, os indícios mostram que o treinamento profissional pode desempenhar um papel relevante para a adoção ou para o aperfeiçoamento das práticas gerenciais praticadas pelos gestores rurais.

Por outro lado, não se obteve significância para a hipótese H7 referente ao possível impacto da escolaridade na adoção das práticas de gestão financeira. Assim, não se pode afirmar que mais anos de ensino formal influenciam os produtores a realizarem a gestão financeira. A não significância desta variável também foi verificada nos estudos de Gloyet al.(2002) e Simioni, Binotto e Battiston (2015), que a associaram à rentabilidade do produtor rural. Esse resultado pode ter relação com o observado por Wilson et al. (2009), que destacaram que produtores graduados ou pós-graduados podem ter outras fontes de renda, de modo que a gestão da propriedade torna-se um fator secundário. Além disso, não se exclui a possibilidade de a formação do produtor tanger áreas do conhecimento que não se associam diretamente ao desenvolvimento de habilidades gerenciais, não impactando, assim, a atuação como gestor rural.

Identificou-se ainda que a idade do produtor impacta de modo positivo a gestão financeira realizada por ele, não se rejeitando a hipótese H9. Esse resultado suporta a afirmação de Wilsonet al.(2009) quanto ao desempenho financeiro ser superior entre produtores mais velhos - caso se considere a relação indicada por Gloy e LaDue (2003) entre a gestão financeira e o desempenho. Para Barros et al. (2015), o aumento da idade reduz a probabilidade de o produtor tornar-se inadimplente, o que pode ser um indicativo da adoção de melhores práticas de gestão. Com base no estudo de Brownet al.(2019), verificou-se que a significância dessa variável persistiu ao ser substituída pela idade ao quadrado, sem impacto no resultado das demais variáveis, o que indica a consistência da associação entre a idade e a gestão financeira realizada pelo produtor. 
Embora a literatura forneça indícios de que a experiência impacta o desempenho e, por conseguinte, as práticas gerenciais(Gloy\&Ladue, 2003; Seramim\& Rojo, 2016; Matemilolaet al., 2018), não houve significância para a hipótese H10, que se refere ao impacto positivo da experiência nas práticas de gestão financeira, uma vez que não houve significância estatística para essa variável. Desse modo, a associação positiva da idade do produtor com as práticas de gestão financeira realizadas por ele não parece decorrer da experiência, e, sim, de outros fatores. Além das hipóteses H2, H7 e H10, também não houve significância para as variáveis endividamento (H4), inadimplência (H5) e tamanho (H8). Assim, não se pode afirmar que esses fatores impactam a adoção de práticas de gestão financeira pelos produtores rurais. A falta de significância estatística da hipótese H8 não suporta os resultados obtidos por Machado Filhoet al.(2017) e Lai et al. (2019), que associaram o tamanho da propriedade a uma maior aderência a práticas gerenciais. Isso pode indicar que os pequenos produtores da amostra tendem a praticar atos de gestão financeira ou que os grandes produtores não os praticam.

O efeito não significativo da variável H5 não corroborou as afirmações de Castagnolo e Ferro (2014), Duan et al. (2018) e Gabbianelli (2018) referentes aos benefícios que as informações geradas pela gestão financeira podem proporcionar para a redução do risco de inadimplência dos clientes. Uma vez que a maioria dos produtores concordou que a inadimplência dos clientes representa uma dificuldade, a não significância dessa variável pode indicar que eles desconhecem as vantagens que uma gestão financeira eficaz pode proporcionar em relação a esse problema. Outra justificativa possível é a redução do risco de inadimplência ao vender a produção de modo indireto, por meio de cooperativas, por exemplo, situação em que uma garantia mais efetiva do recebimento faria com que essa variável não gerasse reflexos na gestão.

Os resultados deste estudo também não se alinharam aos de Camargos et al. (2010) e Barros et al. (2015), que afirmaram haver relação entre o produtor inadimplente e o gerenciamento financeiro. Assim, não se pôde afirmar que existe uma percepção por parte dos produtores rurais endividados de que a gestão financeira pode diminuir os riscos de eles se tornarem inadimplentes.

\section{Testes de Robustez}

A fim de verificar a robustez do modelo e dos resultados obtidos, os testes foram refeitos aplicandose alguns ajustes. Com o objetivo decorroborar o argumento apresentado na análise dos resultados de que a significância da variável Idade não parece decorrer dos anos de experiência na atividade rural, testouse inicialmente, por meio da multiplicação de dummies, o efeito de uma possível interação entre essas variáveis, tendo-se atribuído 1 aos produtores com idade e anos de experiência superiores às respectivas médias e 0 aos produtores que se posicionaram abaixo da medida. Na regressão multivariada, o efeito dessa interação não foi significativo, o que indica uma não associação entre a interação das respostas dos produtores mais velhos e mais experientes com a variável dependente, o que suporta a interpretação realizada na análise dos resultados.

Uma vez que a mensuração das variáveisGF_Realizada e GF_Relevânciaesteve baseada na média de seus respectivos itens, optou-se por tambémreplicar a regressão,alterando-se a forma de obtenção dessas variáveis, ceterisparibus, substituindo-se a média das respostas por cargas fatorais. Este procedimento de análise fatorial é possível, tendo em vista que ambas as variáveis (GF_Realizada e GF_Relevância) foram obtidas a partir de um conjunto de seis questões cada.Para ambas as variáveis, o primeiro fator registrou cargas superiores ao segundo fator em relação àmaioria dos itens. Desse modo, o primeiro fator de cada análise foi selecionado e as variáveis GF_Realizada e GF_Relevânciapassaram a ser mensuradas nesta nova rodada de análises por meio dos scores da análise fatorial. 
Os resultados indicaram que or-quadrado do novo modelo diminuiu para $24,47 \%$, apontando que esse modelo explica menos a variação observada na variável dependente que a versão original. As variáveis correspondentes ao conhecimento dos custos de produção e à percepção sobre a relevância da gestão financeira mantiveram-se significativas, porém a 5\%. A variável Idade, por sua vez, deixou de ser significativa, estando o seu nível de significância, ainda assim, próximo de $10 \%$. Em comparação ao modelo originalmente proposto, não houve alteração no sinal das variáveis e nenhuma nova variável passou a ser significativa após essas alterações.

\section{Considerações finais}

O agronegócio no Brasil possui relevância econômica e social e, conforme demonstrado em estudos anteriores(Medeiroset al., 2012; Kruger et al., 2014), em muitos casos a gestão realizada pelo produtor é precária ou mesmo inexistente, o que pode comprometer seu desempenho e, por conseguinte, gerar impactos negativos para a sociedade e para a economia. A principal contribuição deste estudo, portanto, residiu na compreensão de características que podem influenciar os produtores a desenvolverem a gestão financeira em suas propriedades, o que, por sua vez, pode contribuir para o desenvolvimento de ações que visem esclarecer ou capacitar os gestores rurais a lidarem com gargalos que inviabilizam a prática gerencial.

Os principais resultados do estudo indicaram que capacitar o produtor rural em temas relacionados à gestão financeira pode ser um elemento-chave para que ele adote essas práticas. Simioni, Binotto e Battiston (2015)eNakano et al. (2018) destacaram a relevância de se desenvolver medidas de qualificação profissional do produtor e o presente estudo contribuiu ao demonstrar que essas ações destinadas ao aperfeiçoamento profissional tendem a ter retornos práticos.

A idade também se mostrou como uma característica que se associa à adoção das práticas de gestão financeira, sendo sugerido neste estudo que, de modo semelhante ao indicado porBrownet al. (2019), essa relação decorre da fase ou do estilo de vida do produtor. Em uma análise adicional de robustez, a variável idade deixou de ser significativa, o que indica que o seu efeito pode ser mais forte para determinados tipos de atividades relacionadas à gestão financeira.

A significância obtida para a hipótese $\mathrm{H} 3$ apresentou indícios de que os produtores rurais se preocupam em realizar práticas de gestão necessárias ao conhecimento de seus custos de produção. Em razão dos pontos observados e destacados na estatística descritiva e na hipótese $\mathrm{H} 2$, supôs-se que, apesar do conhecimento sobre os custos de produção, não necessariamente há um controle formal sobre eles. Por fim, a percepção do produtor quanto à relevância das práticas de gestão financeira também é um fator que influencia a administração financeira. Essa informação é relevante, pois demonstra que familiares, sindicatos rurais e Poder Público, entre outros possíveis influenciadores do comportamento do produtor rural, podem auxiliar indiretamente para que este adote práticas gerenciais.

A identificação dessas características associadas aos produtores rurais do Triângulo Mineiro pode colaborar para o desenvolvimento de ações ou políticas públicas voltadas ao setor. Iniciativas nesse sentido podem ser potencializadas ao se conhecerem aspectos associados à regionalidade, de modo que se adequem às particularidades dos produtores da região, além de possibilitar comparações com outras localidades, o que pode subsidiar o desenvolvimento de estratégias integradas. 
Concernente às limitações do estudo, a amostra utilizada foi por conveniência. Dessa forma, os resultados da pesquisa não são necessariamente generalizáveis. De modo semelhante, a delimitação da amostra nos limites do Triângulo Mineiro traz informações úteis sobre os produtores rurais dessa região, mas não permite que os resultados sejam estendidos a outras localidades. Não obstante, destaca-se a relevância informacional de se comparar os resultados obtidos aqui aos obtidos para outras regiões do país, sendo esta uma sugestão para estudos futuros. Uma vez que se optou por gerar uma variável dependente baseada na percepção do produtor rural quanto às suas práticas, torna-se relevante buscar outros meios ou novas escalas para mensurar as ações de gestão financeira praticadas, especialmente por ter havido algumas alterações nos resultados ao se obter as variáveis de gestão financeira por meio da análise fatorial. Assim, sugere-se que estudos futuros proponham novas formas de obtenção dessa variável a fim de confrontar os resultados aqui obtidos.

\section{Referências}

Auzair, S. Md., \&Langfield-Smith, K. (2005).The effect of service process type, business strategy and life cycle stage on bureaucratic MCS in service organizations. Management Accounting Research, 16(4), pp. 399-421. Doi: https://doi.org/10.1016/j.mar.2005.04.003

Bagozzi, R. P., \& Yi, Y. (2011).Specification, evaluation, and interpretation of structural equation models. Journal of the Academy of Marketing Science, 40(1), pp. 8-34. Doi: https://doi.org/10.1007/s11747011-0278-x

Barros, E. de S., Xavier, L. F., Pessoa, D. T., \& Sobel, T. F. (2015). Endividamento agrícola: Quão comprometidos são os produtores do polo Petrolina-Juazeiro frente a suas dívidas? Economia Aplicada, 19(1), pp. 171-200. Doi: https://doi.org/10.1590/1413-8050/ea128281

Borges, M. S., Guedes, C. A. M., \& Castro, M. C. D. e. (2016). Programa de assistência técnica para o desenvolvimento de pequenas propriedades leiteiras em Valença-RJ e região Sul Fluminense. Cadernos EBAPE.BR, 14(spe), pp. 569-592. Doi: https://doi.org/10.1590/1679-395115513

Brown, P., Daigneault, A., \& Dawson, J. (2019).Age, values, farming objectives, past management decisions, and future intentions in New Zealand agriculture.Journalof Environmental Management, 231(1), pp. 110-120. Doi: https://doi.org/10.1016/j.jenvman.2018.10.018

Camargos, M. A. de Camargos, M. C. S., Silva, F. W., Santos, F. S. dos, \& Rodrigues, P. J. (2010). Fatores condicionantes de inadimplência em processos de concessão de crédito a micro e pequenas empresas do Estado de Minas Gerais. Revista de Administração Contemporânea, 14(2), pp. 333-352. Doi: https://doi.org/10.1590/S1415-65552010000200009

Castagnolo, F., \& Ferro, G. (2014). Models for predicting default: Towards efficient forecasts. The Journal of Risk Finance, 15(1), pp. 52-70. Doi: https://doi.org/10.1108/JRF-08-2013-0057

Costa, D. R. de M., Chaddad, F. R., \& Azevedo, P. F. de. (2012). Separação entre propriedade e decisão de gestão nas cooperativas agropecuárias brasileiras. Revista de Economia e Sociologia Rural, 50(2), pp. 285-300. Doi: https://doi.org/10.1590/S0103-20032012000200005

Crespi Júnior, H., Perera, L. C. J., \&Kerr, R. B. (2017). Management of the Cutoff for Granting Consumer Credit.Revista de Administração Contemporânea, 21(2), pp. 269-285. Doi: https://doi. org/10.1590/1982-7849rac2017170025

Datta, S., Tiwari, A. K., \&Shylajan, C. S. (2018). An empirical analysis of nature, magnitude and determinants of farmers' indebtedness in India. International Journal of Social Economics, 45(6), pp. 888-908. Doi: https://doi.org/10.1108/IJSE-11-2016-0319 
Davila, A., \& Foster, G. (2005). Management Accounting Systems Adoption Decisions: Evidence and Performance Implications from Early-Stage/Startup Companies. The Accounting Review, 80(4), pp. 1039-1068.Doi: https://doi.org/10.2308/accr.2005.80.4.1039

Duan, J.-C., Kim, B., Kim, W., \& Shin, D. (2018). Default probabilities of privately held firms. Journal of Banking \& Finance, 94, pp. 235-250. Doi: https://doi.org/10.1016/j.jbankfin.2018.08.006

Eschker, E., Gold, G., \& Lane, M. D. (2017). Rural entrepreneurs: What are the best indicators of their success? Journal of Small Business and Enterprise Development, 24(2), pp. 278-296. Doi: https:// doi.org/10.1108/JSBED-07-2016-0112

Felema, J., Raiher, A. P., \& Ferreira, C. R. (2013). Agropecuária brasileira: Desempenho regional e determinantes de produtividade. Revista de Economia e Sociologia Rural, 51(3), pp. 555-573. Doi: https://doi.org/10.1590/S0103-20032013000300008

Ferreira, J. B., Lasso, S. V., \&Mainardes, E. (2017). Características empreendedoras do produtor rural capixaba. Gestão \& Regionalidade, 33(99), pp. 74-90. Doi: http://dx.doi.org/10.13037/ gr.vol33n99.2943

Fochezatto, A., \&Ghinis, C. P. (2012). Estrutura produtiva agropecuária e desempenho econômico regional: O caso do Rio Grande do Sul, 1996-2008. Revista de Economia e Sociologia Rural, 50(4), pp. 743-762. Doi: https://doi.org/10.1590/S0103-20032012000400009

França, L. M., Mantovaneli Júnior, O.\& Sampaio, C. A. C. (2012). Governança para a territorialidade e sustentabilidade: A construção do senso de regionalidade. Saúde e Sociedade, 21(3), pp. 111-127. Doi: https://doi.org/10.1590/S0104-12902012000700010.

Gabbianelli, L. (2018). A territorial perspective of SME's default prediction models. Studies in Economics and Finance, 35(4), pp. 542-563. Doi: https://doi.org/10.1108/SEF-08-2016-0207

Gloy, B. A., Hyde, J., \&LaDue, E. L. (2002).Dairy Farm Management and Long-Term Farm Financial Performance. Agricultural and Resource Economics Review, 31(2), pp. 1-15. Doi: https://doi. org/10.1017/S1068280500004032

Gloy, B. A., \&LaDue, E. L. (2003).Financial management practices and farm profitability. Agricultural Finance Review, 63(2), pp. 157-174. Doi: https://doi.org/10.1108/00215060380001147

Grøn, C. H. (2018). Perceptions unfolded: Managerial implementation in perception formation. International Journal of Public Sector Management, 31(6), pp. 710-725. Doi: https://doi. org/10.1108/IJPSM-09-2017-0237

Hair, Jr. F., Black, W. C., Babin, B. J., Anderson, R. E., Tatham, R. L.(2009). Análise Multivariada de Dados (6a ed). Porto Alegre: Bookman.

Hey, I. R., \&Morozini, J. F. (2018). A gestão financeira e o ciclo produtivo das commodities agrícolas sob a ótica da Teoria dos Custos de Transação. Custos e @gronegócio, 14(1), pp. 45-73.

Huang, Z., Vyas, V., \& Liang, Q. (2015).Farmer organizations in China and India.China AgriculturalEconomicReview, 7(4), pp. 601-615. Doi: https://doi.org/10.1108/CAER-02-2015-0013

IBGE - Instituto Brasileiro de Geografia e Estatística. (2019). Brasil em Síntese-Minas Gerais. Recuperado 24 de março de 2019, de https://cidades.ibge.gov.br/brasil/mg/pesquisa/10060/60147?localidade1 $=0 \&$ indicador $=60154 \&$ tipo $=$ ranking\&ano $=2016$

Imlau, J. M., Chaves, L. C., Gasparetto, V., Lunkes, R. J., \&Scnorrenberger, D. (2016). Práticas de Gestão em Cooperativas de Produção Agropecuária do Norte do Estado do Rio Grande do Sul. Revista Organizações em Contexto, 12(23), pp. 43-67. Doi: https://doi.org/10.15603/1982-8756/roc.v12n23p43-67 
Islam, Md. Mazharul, Habes,Essam M., \& Alam, Md. Mahmudul. (2018).The Usage and Social Capital of Mobile Phones and Their Effect on the Performance of Microenterprise: An Empirical Study. Technological Forecasting and Social Change, 132, pp. 156-164.Doi: https://doi.org/10.1016/j.techfore.2018.01.029

Khan, M. T. I., Tan, S.-H., \& Chong, L.-L. (2017). Perception of past portfolio returns, optimism and financial decisions. Review of Behavioral Finance, 9(1), pp. 79-98. Doi: https://doi.org/10.1108/ RBF-02-2016-0005

Khanal, A. R., \& Mishra, A. K. (2016). Financial performance of small farm business households: The role of internet. China Agricultural Economic Review, 8(4), pp. 553-571. Doi: https://doi.org/10.1108/ CAER-12-2014-0147

Kruger, S. D., Glustak, E., Mazzioni, S., \&Zanin, A. (2014).A contabilidade como instrumento de gestão dos estabelecimentos rurais. REUNIR: Revista de Administração, Contabilidade e Sustentabilidade, 4(2), pp. 134-153. Doi: https://doi.org/10.18696/reunir.v4i2.246

Kumar, A.,\&Shrestha, S. K. (2014).Decentralizing the Farmer-to-Farmer extension approach to the local level. World Journal of Science, Technology and Sustainable Development, 11(1), pp. 66-77. Doi: https://doi.org/10.1108/WJSTSD-08-2013-0028

Lai, J., Widmar, N. J. O., \& Wolf, C. A. (2019).Dairy farm management priorities and implications. International Food and Agribusiness Management Review, 22(1), 15-30. https://doi.org/10.22434/ ifamr2018.0010

Latawiec, A. E., Strassburg, B. B. N., Silva, D., Alves-Pinto, H. N., Feltran-Barbieri, R., Castro, A., ... Beduschi, F. (2017). Improving land management in Brazil: A perspective from producers. Agriculture, Ecosystems and Environment, 240 (1), pp. 276-286. Doi: https://doi.org/10.1016/j. agee.2017.01.043

Machado Filho, C. P., Caleman, S. M. de Q., \& Cunha, C. F. da. (2017). Governance in agribusiness organizations: Challenges in the management of rural family firms. Revista de Administração, 52(1), pp. 81-92. Doi: https://doi.org/10.1016/j.rausp.2016.09.004

Machado, J. G. C. F., \& Nantes, J. F. D. (2011). Adoção da tecnologia da informação em organizações rurais: O caso da pecuária de corte. Gestão \& Produção, 18(3), pp. 555-570. Doi: https://doi.org/10.1590/ S0104-530X2011000300009

MAPA - Ministério da Agricultura, Pecuária e Abastecimento. (2017, outubro). 70\% dos alimentos que vão à mesa dos brasileiros são da agricultura familiar. Recuperado 22 de março de 2019, de https://www. sna.agr.br/brasil-70-dos-alimentos-que-vao-a-mesa-dos-brasileiros-sao-da-agricultura-familiar/

Martínez-García, C. G., Ugoretz, S. J., Arriaga-Jordán, C. M., \&Wattiaux, M. A. (2015). Farm, household, and farmer characteristics associated with changes in management practices and technology adoption among dairy smallholders. Tropical Animal Health and Production, 47(2), pp. 311-316. Doi: https://doi.org/10.1007/s11250-014-0720-4

Matemilola, B. T., Bany-Ariffin, A. N., Azman-Saini, W. N. W., \& Nassir, A. M. (2018). Does top managers' experience affect firms' capital structure? Research in International Business and Finance, 45(C), pp. 488-498. Doi: https://doi.org/10.1016/j.ribaf.2017.07.184

Mazzioni, S., Zanin, A., Kruger, S. D., \& Rocha, J. L. K. (2007). A Importância dos controles gerenciais para o agribusiness. Revista Catarinense da Ciência Contábil, 6(16), pp. 9-26. Doi: https://doi. org/10.16930/2237-7662/rccc.v6n16p9-26 
Medeiros, A. F. Q., Porto, W. S., Souza, J. A., \& Oliveira, D. de L. (2012). Controle e apuração de resultado na agricultura familiar sob a ótica da sustentabilidade de produtores rurais. Custos e @gronegócio online, 8(3), pp. 154-171.Recuperado dehttp://www.custoseagronegocioonline.com.br/numero3v8/ controle.pdf

Miller, D., \& Friesen, P. H. (1984).A Longitudinal Study of the Corporate Life Cycle. Management Science, 30(10), pp. 1161-1183.Doi: http://dx.doi.org/10.1287/mnsc.30.10.1161

Mion, G., \&Opromolla, L. D. (2014).Managers' mobility, trade performance, and wages. Journal of International Economics, 94(1), pp. 85-101. Doi: https://doi.org/10.1016/j.jinteco.2014.06.001

Miotto, A. P. S. C., \& Parente, J. (2015). Antecedents and consequences of household financial management in Brazilian lower-middle-class.Revista de Administração de Empresas, 55(1), pp. 50-64. Doi: https://doi.org/10.1590/S0034-759020150106

Nakano, Y., Tsusaka, T. W., Aida, T., \& Pede, V. O. (2018). Is farmer-to-farmer extension effective? The impact of training on technology adoption and rice farming productivity in Tanzania. World Development, 105, pp. 336-351. Doi: https://doi.org/10.1016/j.worlddev.2017.12.013

Ndemewah, S. R., Menges, K., \&Hiebl, M. R. W. (2019). Management accounting research on farms: What is known and what needs knowing? Journal of Accounting \& Organizational Change, 15(1), pp. 58-86. Doi: https://doi.org/10.1108/JAOC-05-2018-0044

Nyanga, P. H., Johnsen, F. H., Aune, J. B., \&Kalinda, T. H. (2011). Smallholder Farmers' Perceptions of Climate Change and Conservation Agriculture: Evidence from Zambia. Journal of Sustainable Development, 4(4), pp. 73-85. Doi: https://doi.org/10.5539/jsd.v4n4p73

Oaigen, R. P., Barcellos, J. O. J., Canozzi, M. E. A., Soares, J. C. dos R., Canellas, L. C., Alves, C. O., ... Costa, F. M. da. (2013). Competitividade inter-regional de sistemas de produção de bovinocultura de corte. Ciência Rural, 43(8), pp. 1489-1495. Doi: https://doi.org/10.1590/S0103-84782013000800024

O'Reilly, D. M. (2009). Do investors perceive the going-concern opinion as useful for pricing stocks? Managerial Auditing Journal, 25(1), pp. 4-16. Doi: https://doi.org/10.1108/02686901011007270

Pauw, P. (2013). The role of perception in subsistence farmer adaptation in Africa: Enriching the climate finance debate. International Journal of Climate Change Strategies and Management, 5(3), pp. 267284. Doi: https://doi.org/10.1108/IJCCSM-03-2012-0014

Robinson, S. L., Taylor, R. G., \& Brice, Jr., Jeff. (2016). Perception deception: Security risks created by optimistic perceptions. Journal of Systems and Information Technology, 18(1), pp. 2-17. Doi: https://doi.org/10.1108/JSIT-07-2015-0062

Seramim, R. J.,\& Rojo, C. A. (2016). Gestão dos custos de produção da atividade leiteira na agricultura familiar. Revista Gestão \& Tecnologia, 16(3), pp. 244-260. Doi: https://doi.org/10.20397/21776652/2016.v16i3.941

Simioni, F. J.,Binotto, E., \&Battiston, J. (2015). Informação e gestão na agricultura familiar da região Oeste de Santa Catarina. Revista Brasileira de Gestão e Desenvolvimento Regional, 11(3), pp. 152-177. Recuperado dehttps://www.rbgdr.net/revista/index.php/rbgdr/search/search?query=Informa\%C $3 \% \mathrm{~A} 7 \% \mathrm{C} 3 \% \mathrm{~A} 3 \mathrm{o}+\mathrm{e}+$ gest $\% \mathrm{C} 3 \% \mathrm{~A} 3 \mathrm{o}+$ na + agricultura + familiar+da+regi $\% \mathrm{C} 3 \% \mathrm{~A} 3 \mathrm{o}+\mathrm{Oeste}+\mathrm{de}+\mathrm{Sa}$ nta + Catarina\&authors $=\&$ title $=\&$ abstract $=\&$ galleyFullText $=\&$ suppFiles $=\&$ dateFromMonth $=\& \mathrm{~d}$ ateFromDay $=\&$ dateFrom Year $=\&$ dateToMonth $=\&$ dateToDay $=\&$ dateToYear $=\&$ dateToHour $=23 \&$ dateToMinute $=59 \&$ dateToSecond $=59 \&$ discipline $=\&$ subject $=\&$ type $=\&$ coverage $=\&$ indexTerms $=$

Sjahza, A., \&Asmit, B. (2019).Regional economic empowerment through oil palm economic institutional development. Management of Environmental Quality, 30(6), pp. 1256-1278. Doi: https://doi. org/10.1108/MEQ-02-2018-0036 
Tarifa, M. R., \&Schallenberger, E. (2016). Gestão Cooperativa, Ambiente Institucional e Sociocultural: O caso Brasil-Paraguai. Revista de Economia e Sociologia Rural, 54(4), pp. 615-634. Doi: https://doi. org/10.1590/1234-56781806-94790540402

Vogel, J., \& Wood Jr., T. (2012). Práticas gerenciais de pequenas empresas industriais do Estado de São Paulo: Um Estudo Exploratório. Revista de Empreendedorismo e Gestão de Pequenas Empresas, 1(2), pp. 117-140. Doi: http://dx.doi.org/10.14211/regepe.vli2.34

Wilson, C., Mishra, A., \& Williams, R. (2009).Factors affecting financial performance of new and beginning farmers. Agricultural Finance Review, 69(2), pp. 160-179. Doi: https://doi. org/10.1108/00021460910978661

Zanin, A., Oenning, V., Tres, N., Kruger, S. D., \&Gubiani, C. A. (2014). Gestão das propriedades rurais do Oeste de Santa Catarina: As fragilidades da estrutura organizacional e a necessidade do uso de controles contábeis. Revista Catarinense da Ciência Contábil, 13(40), pp. 9-19. Doi: http://dx.doi. org/10.16930/2237-7662/rccc.v13n40p9-19 


\section{Apêndice A. Matriz de Correlação entre as Variáveis do Estudo}

\begin{tabular}{|c|c|c|c|c|c|c|c|c|c|c|c|c|}
\hline Variáveis & & (1) & $(2)$ & (3) & (4) & (5) & (6) & (7) & (8) & (9) & (10) & (11) \\
\hline GF-Realizada & (1) & 1,000 & & & & & & & & & & \\
\hline \multirow{2}{*}{ GF-Relevância } & \multirow{2}{*}{ (2) } & 0,363 & 1,000 & & & & & & & & & \\
\hline & & 0,000 & & & & & & & & & & \\
\hline \multirow{2}{*}{ Tamanho (Ln) } & \multirow{2}{*}{ (3) } & 0,177 & 0,055 & 1,000 & & & & & & & & \\
\hline & & 0,057 & 0,560 & & & & & & & & & \\
\hline \multirow{2}{*}{ Idade (anos) } & \multirow{2}{*}{ (4) } & 0,051 & $-0,214$ & 0,073 & 1,000 & & & & & & & \\
\hline & & 0,591 & 0,022 & 0,440 & & & & & & & & \\
\hline \multirow{2}{*}{ Experiência (anos) } & \multirow{2}{*}{ (5) } & $-0,102$ & $-0,282$ & 0,058 & 0,591 & 1,000 & & & & & & \\
\hline & & 0,278 & 0,002 & 0,542 & 0,000 & & & & & & & \\
\hline \multirow{2}{*}{ Escolaridade } & \multirow{2}{*}{ (6) } & 0,256 & 0,234 & 0,247 & $-0,227$ & $-0,182$ & 1,000 & & & & & \\
\hline & & 1,000 & 0,013 & 0,009 & 0,016 & 0,053 & & & & & & \\
\hline \multirow{2}{*}{ Inadimplência } & \multirow{2}{*}{ (7) } & 0,080 & 0,078 & $-0,138$ & $-0,152$ & $-0,114$ & 0,023 & 1,000 & & & & \\
\hline & & 0,393 & 0,405 & 0,140 & 0,106 & 0,226 & 0,811 & & & & & \\
\hline \multirow{2}{*}{$\begin{array}{l}\text { Possui Ferram. } \\
\text { Contr.? }\end{array}$} & \multirow{2}{*}{ (8) } & 0,347 & 0,301 & 0,187 & $-0,221$ & $-0,237$ & 0,358 & 0,062 & 1,000 & & & \\
\hline & & 0,000 & 0,001 & 0,047 & 0,019 & 0,012 & 0,000 & 0,514 & & & & \\
\hline \multirow{2}{*}{$\begin{array}{l}\text { Conhec. Custo } \\
\text { Produção? }\end{array}$} & \multirow{2}{*}{ (9) } & 0,392 & 0,157 & 0,171 & $-0,077$ & $-0,148$ & 0,194 & 0,073 & 0,381 & 1,000 & & \\
\hline & & 0,000 & 0,097 & 0,070 & 0,421 & 0,117 & 0,040 & 0,441 & 0,000 & & & \\
\hline \multirow{2}{*}{$\begin{array}{l}\text { Treinam. Gest. } \\
\text { Financ.? }\end{array}$} & \multirow{2}{*}{ (10) } & 0,331 & 0,223 & 0,063 & $-0,223$ & $-0,069$ & 0,479 & 0,117 & 0,348 & 0,123 & 1,000 & \\
\hline & & 0,000 & 0,018 & 0,509 & 0,018 & 0,465 & 0,000 & 0,216 & 0,000 & 0,194 & & \\
\hline \multirow{2}{*}{ Endividado? } & \multirow{2}{*}{ (11) } & $-0,081$ & 0,057 & 0,110 & 0,009 & 0,162 & 0,034 & 0,118 & $-0,065$ & $-0,061$ & 0,033 & 1,000 \\
\hline & & 0,397 & 0,552 & 0,244 & 0,923 & 0,086 & 0,721 & 0,212 & 0,498 & 0,519 & 0,727 & \\
\hline
\end{tabular}

Notas: a parte superior de cada linha evidencia o coeficiente de correlação de Pearson entre as variáveis; a parte inferior indica o nível de significância. 


\section{Apêndice B. Análise adicional sobre o efeito das variáveis idade e experiência}

\begin{tabular}{|c|c|c|}
\hline \multirow{2}{*}{ Variáveis } & \multicolumn{2}{|c|}{ Modelo Completo } \\
\hline & Coef. & signif. \\
\hline GF_Relevância & 0,493 & $0,002 * * *$ \\
\hline Ferramentas de Controle & 0,139 & 0,300 \\
\hline Conhecimento Custos de Produção & 0,525 & $0,007 * * *$ \\
\hline Endividamento & $-0,206$ & 0,229 \\
\hline Inadimplência & 0,048 & 0,479 \\
\hline Treinamento em Gestão Financeira & 0,387 & $0,007 * \star \star$ \\
\hline Escolaridade & 0,015 & 0,844 \\
\hline Tamanho (Ln) & 0,047 & 0,246 \\
\hline Idade (anos) & 0,013 & $0,016 * \star$ \\
\hline Experiência (anos) & $-0,004$ & 0,423 \\
\hline constante & $-0,028$ & 0,972 \\
\hline número de observações: & 113 & \\
\hline r-quadrado: & $36,46 \%$ & \\
\hline r-quadrado ajustado: & $30,23 \%$ & \\
\hline
\end{tabular}

\begin{tabular}{ll}
\hline \multicolumn{2}{c}{ Modelo s/ Exper. } \\
\hline Coef. & \multicolumn{1}{c}{ signif. } \\
\hline 0,515 & $0,0022^{* * *}$ \\
\hline 0,147 & 0,262 \\
\hline 0,533 & $0,006{ }^{* * *}$ \\
\hline$-0,237$ & 0,157 \\
\hline 0,053 & 0,421 \\
\hline 0,368 & $0,009{ }^{* * *}$ \\
\hline 0,020 & 0,796 \\
\hline 0,046 & 0,258 \\
\hline 0,011 & $0,014 * *$ \\
\hline & \\
\hline$-0,135$ & 0,867 \\
\hline 113 & \\
\hline $36,09 \%$ & \\
\hline $30,51 \%$ & \\
\hline
\end{tabular}

\begin{tabular}{|c|c|}
\hline \multicolumn{2}{|c|}{ Modelo s/ Idade } \\
\hline Coef. & signif. \\
\hline 0,495 & $0,003 * * *$ \\
\hline 0,119 & 0,380 \\
\hline 0,545 & $0,005 * * *$ \\
\hline$-0,257$ & 0,168 \\
\hline 0,044 & 0,502 \\
\hline 0,329 & $0,029 * *$ \\
\hline 0,004 & 0,963 \\
\hline 0,056 & 0,180 \\
\hline 0,487 & 0,547 \\
\hline 113 & \\
\hline $32,55 \%$ & \\
\hline $26,66 \%$ & \\
\hline
\end{tabular}

Notas: ${ }^{*} p<0.10 ; * * p<0.05 ; * \star * p<0.01$

Fonte: Resultados da pesquisa. 